\title{
BMJ Open Sociodemographic, lifestyle and metabolic predictors of all-cause mortality in a cohort of community- dwelling population: an 18-year follow- up of the North West Adelaide Health Study
}

\author{
Yohannes Adama Melaku, ${ }^{1}$ Tiffany K Gill, ${ }^{2}$ Sarah L Appleton, ${ }^{1,3,4}$ Catherine Hill, ${ }^{2,5}$ \\ Mark A Boyd, ${ }^{6,7}$ Robert J Adams ${ }^{1,3,4}$
}

To cite: Melaku YA, Gill TK, Appleton SL, et al. Sociodemographic, lifestyle and metabolic predictors of all-cause mortality in a cohort of community-dwelling population: an 18-year followup of the North West Adelaide Health Study. BMJ Open 2019;9:e030079. doi:10.1136/ bmjopen-2019-030079

- Prepublication history and additional material for this paper are available online. To view these files, please visit the journal online (http://dx.doi. org/10.1136bmjopen-2019030079).

Received 26 February 2019 Revised 26 June 2019 Accepted 26 July 2019

A) Check for updates

(c) Author(s) (or their employer(s)) 2019. Re-use permitted under CC BY-NC. No commercial re-use. See rights and permissions. Published by BMJ.

For numbered affiliations see end of article.

\section{Correspondence to} Dr Yohannes Adama Melaku; yohannes.melaku@flinders. edu.au

\section{ABSTRACT}

Introduction Studies examining potential factors of all-cause mortality comprehensively at community level are rare. Using long-term community-based follow-up study, we examined the association of sociodemographic and behavioural characteristics, metabolic and chronic conditions, and medication and health service utilisation with all-cause mortality.

Methods We followed 4056 participants, aged 18-90 years, for 18 years in the North West Adelaide Health Study (NWAHS). Mortality data were obtained from South Australian (SA) public hospitals and registries including SA births, deaths and marriages, the National Death Index and the NWAHS follow-up. Predictors of all-cause mortality were explored using Cox proportional hazard model, adjusting for potential confounders. We performed subgroup analyses by sex and age.

Results Mean (SD) age at baseline was 50.4 (16.4) years. Less than half (47.8\%) of the participants were men. A total of 64689.7 person-years from 4033 participants with 18.7 years of follow-up were generated. The median follow-up time was 17.7 years; 614 deaths were recorded. The overall crude death rate was $9.6(95 \% \mathrm{Cl} 8.9$ to 10.4) per 1000 person-years. After adjusting for potential confounders, a reduced risk of mortality was significantly associated with being separated or divorced, being in the highest Socioeconomic Indexes for Areas quintile, engaging in moderate exercise, being overweight (body mass index: $25.0-29.9 \mathrm{~kg} / \mathrm{m}^{2}$ ) and per $10 \%$ increase in per cent predicted forced expiratory volume in $1 \mathrm{~s}$. We found that the most important predictors of all-cause mortality were sociodemographic and behavioural characteristics. Sociodemographic factors were more important predictors of all-cause mortality in young age bracket compared with older people.

Conclusions Socioeconomic factors were found to be the most important predictors of all-cause mortality. The study highlights the need to address the social inequalities and strengthen behavioural interventions for different subgroups of population to prevent premature deaths.
Strengths and limitations of this study

- This study used data from a prospective community-based long-term follow-up study.

- The study included comprehensive risk factors (sociodemographic, behavioural and metabolic factors, and health service and medication utilisation) associated with mortality.

- A thorough characterisation of risk factors and their contribution to all-cause mortality was conducted.

- Missing covariates values were main limitations of this study.

\section{INTRODUCTION}

Globally, an estimated 55.9 million deaths occurred in 2017 , of which $73.4 \%$ were due to non-communicable chronic diseases (NCDs). Cardiovascular diseases (CVDs) (17.8 million), cancer (9.6 million) and chronic respiratory diseases (3.9 million) were the leading causes of death. In high-income countries, of 9.7 million deaths in 2017 , $88.8 \%$ were due to NCDs. Nine in 10 of 170 873 deaths that occurred were due to NCDs. ${ }^{1}$ In Australia, half of deaths that occurred among people less than 75 years in 2016 were premature. ${ }^{2}$ Behavioural, metabolic and environmental/occupational factors contributed to most of the deaths in high-income countries including Australia. ${ }^{3}$

In high-income countries, social inequalities, as indicated by educational status, occupational class or income level, continue to be a major contributor to premature deaths. ${ }^{4}$ In addition, behavioural factors are major contributors. Studies have shown that social inequalities could have an impact on behavioural and metabolic risk factors ${ }^{5-7}$ 


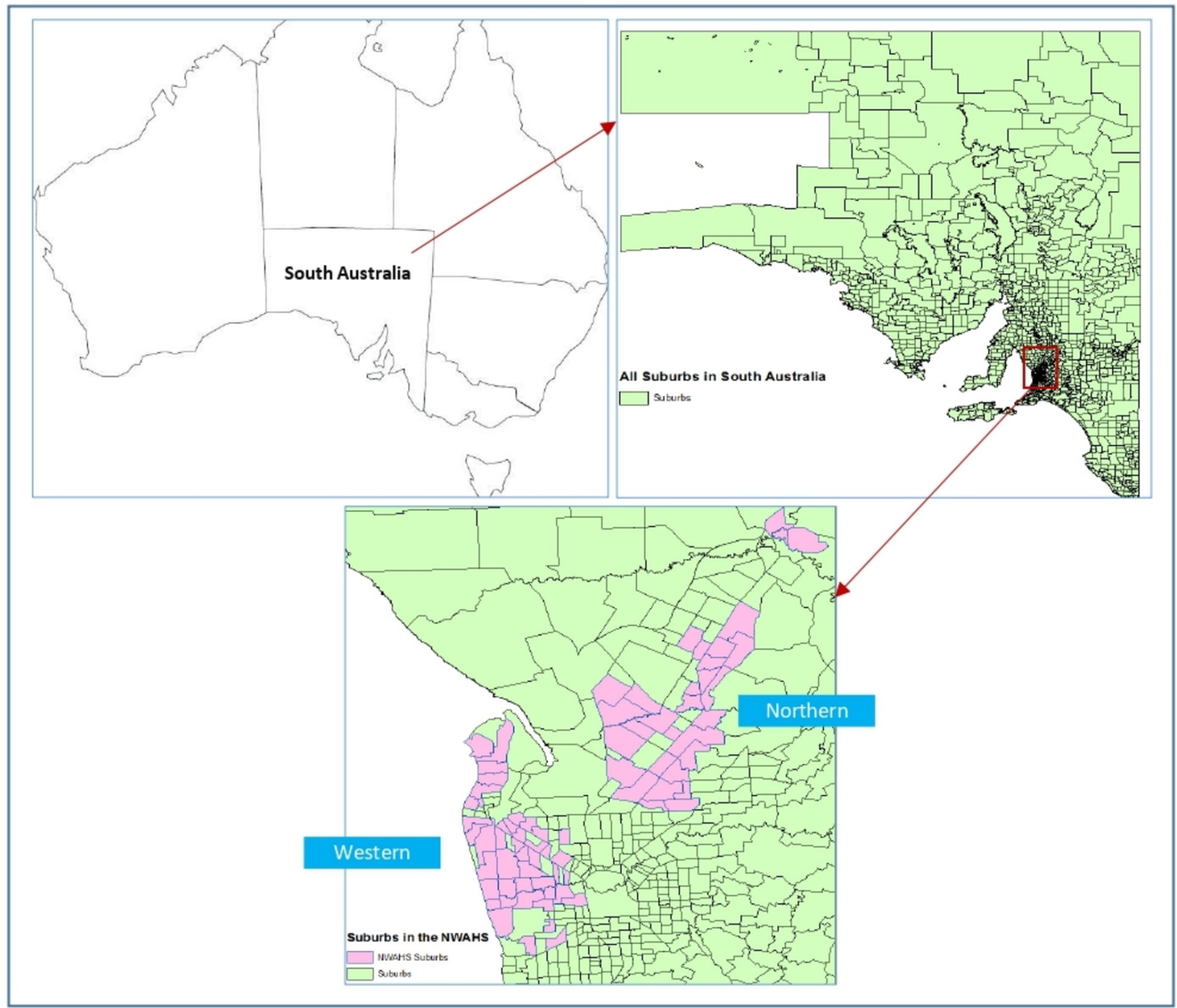

Figure 1 Map of the study area. NWAHS, North West Adelaide Health Study.

eventually increasing the susceptibility to chronic diseases and premature deaths. Previous studies have demonstrated that social inequalities, ${ }^{48}$ psychosocial factors, ${ }^{9} 10$ behavioural ${ }^{8}$ and metabolic risk factors ${ }^{11-13}$ are important predictors of all-cause mortality. However, these studies either did not have adequate follow-up time, used only one or two clusters of factors (sociodemographic, behavioural, metabolic or clinical data), did not comprehensively consider all predictors or were not community based. In addition, the studies did not evaluate the role of residential area in predicting mortality and modifying the association between other factors and mortality.

The aim of this study was to explore in detail the association of sociodemographic and behavioural characteristics, metabolic factors, chronic conditions, medication use and health service utilisation with all-cause mortality in a community-dwelling population cohort followed for nearly two decades. We systematically explored the role of clusters of factors (sociodemographic, behavioural, metabolic and chronic conditions) in predicting all-cause mortality. We also estimated the association by population subgroups (sex and age) and investigated the relative contribution of factors predicting mortality and effect modification by participants' characteristics.

\section{METHODS}

\section{Study design and population}

We used data from the North West Adelaide Health Study (NWAHS), which is a community-based longitudinal biomedical study in the Northern and Western suburbs of the city of Adelaide, South Australia. One-third of the South Australian (SA) population and half of the metropolitan area of the Adelaide Central Business District were included in the Northern and Western regions at baseline (figure 1). 


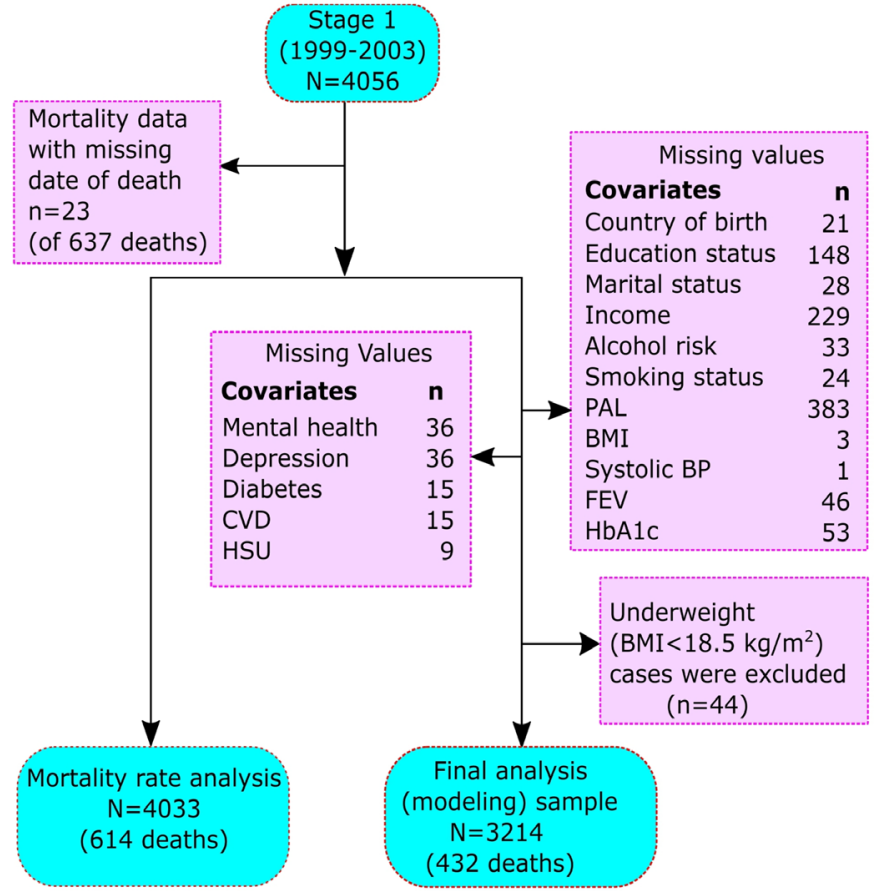

Figure 2 Sample description. BMI, body mass index; BP, blood pressure; CVD, cardiovascular disease; FEV, forced expiratory volume; HbA1c, glycosylated haemoglobin; HSU, health service utilisation; PAL, physical activity level.

The purpose of NWAHS was to collect social, behavioural, clinical and biomedical data to support decision and policy-making. The details of the study are published elsewhere. ${ }^{14}$ In brief, three stages of data collection were undertaken-each occurred approximately 5 years apart (1999-2003, 2004-2006 and 2008-2010). Participants were randomly recruited using computer-assisted telephone interviews (CATI). Initially, phone numbers from the Northern and Western part of Adelaide (South Australia), which were connected to a landline telephone, were randomly selected using the Adelaide telephone directory (electronic 'White Pages') with no replacement for non-response excluding businesses and disconnected numbers (eligible sample $\mathrm{N}=8213$ ). Individuals residing in the selected household aged 18 years and over were candidates for the study. All covariates used in this study were collected at stage 1 by CATI, survey questionnaires and clinical assessment $(\mathrm{N}=4056)$. At stage 1 , complete data on all covariates of interest were available to 3214 participants (figure 2).

\section{Covariates}

Questionnaires were used to determine baseline characteristics including sociodemographics (place of residence, age, sex, country of birth, educational status, marital status, income and Socioeconomic Indexes for Areas (SEIFA)), behavioural factors (alcohol risk, ${ }^{15}$ smoking and physical activity level (PAL) ${ }^{1617}$ ) and doctor diagnosed chronic health conditions (mental health, depression and CVD, including myocardial infarction, angina, stroke, transient ischaemic attack), medication (medication for hypertension, respiratory diseases and high cholesterol) and health service utilisation in the 12 months prior to data collection. SEIFA scores were summarised in five quintiles, the first indicating the least advantaged. SEIFA is an index developed by the Australian Bureau of Statistics and ranks areas in Australia according to socioeconomic advantage and disadvantage. ${ }^{18}$

Clinic assessments included anthropometry, postbronchodilator spirometry (for percentage of predicted forced expiratory volume in $1 \mathrm{~s}\left(\mathrm{FEV}_{1}\right)$ (per cent predicted $\left.\mathrm{FEV}_{1}\right)$ ) and measures of blood pressure as previously described. $^{14}$ A fasting blood sample was drawn for measures of glucose and glycated haemoglobin (HbAlc), however, we used $\mathrm{HbAlc}$ in preference to glucose as an indicator of glycaemic control because it indicates blood sugar levels over the previous weeks to months compared with a fasting glucose level. ${ }^{20}$ Diabetes was determined by self-report of a doctor diagnosis or fasting plasma glucose $\geq 7.0 \mathrm{mmol} / \mathrm{L}$.

\section{Outcome assessment}

We used mortality data from SA public hospitals, and registries including SA births, deaths and marriages, the National Death Index, and the NWAHS stages 2 and 3. The mortality datasets consisted of participants' identification number (assigned at stage 1 of NWAHS), date of death and cause of death based on the International Classification of Disease-10 classification.

A total of 637 participants died during the follow-up time. We were unable to determine the exact date of death for 23 deceased participants. Hence, we used 614 deceased cases for mortality rate analysis. After excluding participants with missing covariates and those who were classified as underweight $(\mathrm{n}=44), 432$ deceased participants were included in the final analysis (figure 1). Participants were censored at the date of death if they were deceased or at the last date of update (15 August 2018) otherwise.

\section{Statistical analysis}

$\chi^{2}$ (categorical variables) and analysis of variance (normally distributed continuous variables) tests were used where appropriate to compare differences in proportions and means of groups at baseline by region of residence. Time to the incident event was determined as the time from date of NWAHS baseline clinical assessment to mortality. Follow-up was censored at the date of death or end of follow-up whichever came first.

We calculated the incidence rate (per 1000 personyears) of mortality by selected covariates (region of residence, sex, income and diabetes status) of residence and the log-rank test was used to investigate the differences. In addition, Kaplan-Meier survival estimates were calculated over the follow-up time.

To assess the association of covariates with incident mortalities, hazard ratios (HRs) were determined using Cox proportional hazard regression models. Underweight participants $(n=44)$ were excluded from this 
analysis because of the possibility of reverse causality, as these participants could have end-stage debilitating diseases leading to death soon after baseline data collection that might bias effect estimates. Variables with $\mathrm{p} \leq 0.25$ in the univariate Cox regression were included in the multivariable models. To identify important predictors of mortality, four models were developed: model 1 was adjusted for region, age, sex, educational status, income, SEIFA and country of birth; model 2 was additionally adjusted for smoking, physical activity and alcohol intake; Model 3 was additionally adjusted for body mass index (BMI), per cent predicted $\mathrm{FEV}_{1}$ and HbA1c; model 4 was additionally adjusted for mental health status, depression, hypertension, diabetes, CVD, hypertension medication, respiratory medication, cholesterol-lowering drug use and health service utilisation. To investigate clustering of mortality by postal code, we performed a Cox regression analysis with shared frailty.

We calculated proportion of reduction in HR of income after adjusting for behavioural, metabolic, chronic conditions, medication and health service utilisation. This was calculated as: (HR (model 1)-HR (model 2 or 3 or 4)/1-HR (model 1))*100. The change in HR was interpreted as to the extent of association between income and all-cause mortality that was accounted for by the other factors. ${ }^{21}$

We investigated sex-specific and age-specific $(<65$ years and older $\geq 65$ years) association of each variable with all-cause mortality to identify predictors of mortality among younger ( $<65$ years) and older ( $\geq 65$ years) participants. We tested interactions among covariates using multiplicative terms in the last model (model 4). The assumption of proportionality was tested using different approaches, including a global test based on Schoenfeld residuals, log-rank test and graphical methods. All tests indicated that the proportionality assumptions were not violated. For each model, we additionally checked the model specifications, goodness-of-fit and predictive performance using the Breslow method, Cox-Snell residual method, Harrell's C and Somers' D indices. ${ }^{22}$ Whereas the Harrell's C index a measure of area under the curve for survival data, Homers' D-index indicates the predictive performance of models. We also calculated the Akaike and Bayesian information criteria. The Breslow method indicated that the models were correctly specified. Furthermore, the models were evaluated for multicollinearity. Statistical analyses were performed using Stata V.15.1 (Stata). All p values are two sided and considered significant if $\mathrm{p}<0.05$.

\section{Sensitivity analysis}

In addition to the main analysis, we conducted five sensitivity analysis using model 4 to check the robustness of the model and validate our findings. First, we excluded participants who were followed only for the first 2 years. Second, we excluded those who moved in/out of/from North and/or West $(n=292)$ using data from stages 2 and 3. Third, we included 'missing' as variable categories for those missing values and investigated the association between predictors and the outcome. Fourth, we performed a multiple imputation for exercise level $(n=383)$, income $(n=229)$ and education $(n=148)$ as these had the highest proportion of missing values. Finally, we limited our analysis (model 4) for those who had no diabetes and CVD at baseline) and those who did not take medications (antihypertensive and respiratory disease medications, and cholesterol-lowering drugs).

\section{PATIENT AND PUBLIC INVOLVEMENT}

This is a population-based study examining randomly selected residents of Adelaide, South Australia. The results of the study have been disseminated to participants broadly using various means including newsletters and community presentations. In addition, individual participants were informed about the results of their clinical assessments.

\section{RESULTS}

\section{Baseline characteristics}

Table 1 shows the baseline characteristics of study participants by region. Of the 4056 study participants enrolled, missing data of at least one covariate were found in 791 $(19.5 \%)$ participants. PAL $(n=383)$, income $(n=229)$ and educational status $(n=148)$ had the most common missing values. The mean (SD) age and range at the baseline were $50.4(16.9)$ and 18-90 years, respectively. Less than half $(47.8 \%)$ of the participants were men. More than two-thirds $(68.5 \%)$ of the participants were born in Australia and one-third (36.9\%) were in the first (lowest) quintile of SEIFA. A quarter (25.5\%) had a sedentary life (no physical activity) and $22.0 \%$ were current smokers. The prevalence of obesity was $28.6 \%$. Mean (SD) systolic blood pressure was $128 \mathrm{~mm} \mathrm{Hg}$ (19.0). Fourteen per cent reported a doctor had diagnosed mental health problem. The prevalence of diabetes and CVD was $8.0 \%$. Eight per cent and $5.2 \%$ of the participants used antihypertensive and cholesterol lowering medications, respectively. A significant difference by region of residence was observed for age, country of birth, educational status, income, SEIFA, smoking status, PAL, BMI category, per cent predicted $\mathrm{FEV}_{1}, \mathrm{HbAlc}$, health service utilisation, hypertension and respiratory medication use.

\section{All-cause mortality rates}

A total of 64689.7 person-years from 4033 participants with 18.7 years of follow-up were generated. The median follow-up time was 17.7 years. In the mortality rate analysis, 614 deaths were included. The overall crude death rate was 9.6 (95\% CI 8.9 to 10.4) per 1000 person-years. Mortality rates by selected variables are depicted in online supplementary table 1 . The crude mortality rate in the Western region was higher $(10.7 ; 95 \%$ CI 9.7 to 11.9 ; per 1000 person-years) than the Northern $(8.2 ; 95 \%$ CI 7.2 to 9.4). The mortality rate was 12.1 (95\% CI 10.9 to 13.4 ) in 
Table 1 Baseline characteristics of study participants (stage 1, n=4056)

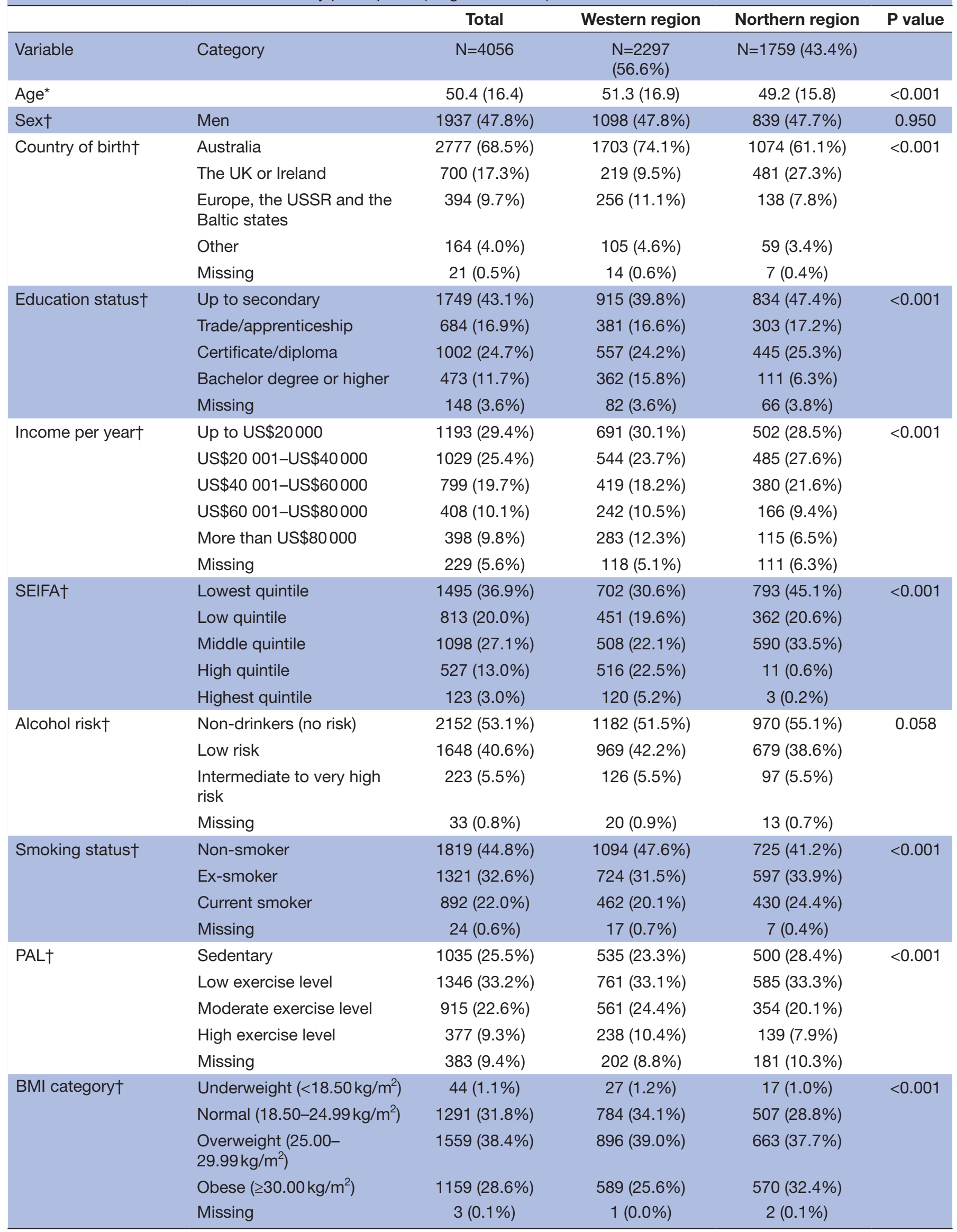


Table 1 Continued

\begin{tabular}{|c|c|c|c|c|c|}
\hline & & Total & Western region & Northern region & $P$ value \\
\hline \multicolumn{2}{|l|}{$\begin{array}{l}\text { Systolic blood pressure } \\
(\mathrm{mm} \mathrm{Hg})^{\star}(n=4055)\end{array}$} & $128.0(19.0)$ & $12.7(1.9)$ & $12.9(1.9)$ & 0.072 \\
\hline \multicolumn{2}{|l|}{$\begin{array}{l}\% \text { predicted } \mathrm{FEV}_{1}{ }^{*} \\
(\mathrm{n}=4010)\end{array}$} & $100.1(17.0)$ & $9.9(1.7)$ & $10.2(1.7)$ & $<0.001$ \\
\hline \multicolumn{2}{|l|}{$\operatorname{HbA1c}(\%)^{\star}(n=4003)$} & $5.6(0.8)$ & $5.7(0.7)$ & $5.4(0.8)$ & $<0.001$ \\
\hline \multirow[t]{2}{*}{ Mental health problem $†$} & Yes & $586(14.4 \%)$ & $313(13.6 \%)$ & $273(15.5 \%)$ & 0.140 \\
\hline & Missing & $36(0.9 \%)$ & $36(1.6 \%)$ & $0(0.0 \%)$ & \\
\hline \multirow[t]{2}{*}{ Depression† } & Yes & $328(8.1 \%)$ & $173(7.5 \%)$ & $155(8.8 \%)$ & 0.180 \\
\hline & Missing & $36(0.9 \%)$ & $36(1.6 \%)$ & $0(0.0 \%)$ & \\
\hline \multirow[t]{2}{*}{ Diabetest } & Yes & $324(8.0 \%)$ & $174(7.6 \%)$ & $150(8.5 \%)$ & 0.270 \\
\hline & Missing & $15(0.4 \%)$ & $8(0.3 \%)$ & $7(0.4 \%)$ & \\
\hline \multirow[t]{2}{*}{ CVD† } & Yes & $326(8.0 \%)$ & $192(8.4 \%)$ & $134(7.6 \%)$ & 0.380 \\
\hline & Missing & $6(0.1 \%)$ & $6(0.3 \%)$ & $0(0.0 \%)$ & \\
\hline $\begin{array}{l}\text { Hypertension } \\
\text { medication } \dagger\end{array}$ & Yes & $314(7.7 \%)$ & $212(9.2 \%)$ & $102(5.8 \%)$ & $<0.001$ \\
\hline $\begin{array}{l}\text { Respiratory disease } \\
\text { medicationt }\end{array}$ & Yes & $132(3.3 \%)$ & $95(4.1 \%)$ & $37(2.1 \%)$ & $<0.001$ \\
\hline $\begin{array}{l}\text { Cholesterol lowering } \\
\text { drugs } †\end{array}$ & Yes & $212(5.2 \%)$ & $126(5.5 \%)$ & $86(4.9 \%)$ & 0.400 \\
\hline $\begin{array}{l}\text { Health service use } \\
(n=4047)\end{array}$ & & $2.4(1.5)$ & $2.4(1.5)$ & $2.3(1.5)$ & 0.003 \\
\hline
\end{tabular}

Data are presented as mean (SD) for continuous measures, and $\mathrm{n}(\%)$ for categorical measures.

${ }^{*}$ Analysis of variance.

$\dagger X^{2}$ test.

BMI, body mass index; CVD, cardiovascular disease; FEV , forced expiratory volume in $1 \mathrm{~s}$; HbA1c, glycosylated haemoglobin; PAL, physical activity level; SEIFA, Socioeconomic Indexes for Areas; USSR, Union of Soviet Socialist Republics.

men and 7.5 (95\% CI 6.6 to 8.4) per 1000 person-years in women. Ex-smokers had higher mortality rate $(13.3$ (95\% CI 11.8 to 15.0$)$ per 1000 person-years) compared with non-smokers $(8.0 ; 95 \%$ CI 7.0 to 9.1$)$ and current smokers $(7.8 ; 95 \%$ CI 6.5 to 9.4$)$. Mortality rate was significantly higher in those who took medications to manage hypertension, respiratory disease and cholesterol compared with those who did not take these medications.

Kaplan-Meier survival estimates and log-rank $x^{2}$ test for sex, income, region of residence and diabetic status are depicted in figure 3 .

\section{Predictors of all-cause mortality}

Adjusted HRs for 18-year mortality by baseline characteristics in four models are shown in table 2. In model 1 (adjusted for sociodemographic characteristics), sex, income and SEIFA were found to be significantly associated with risk of mortality. Women had a $43 \%$ (HR $0.57 ; 95 \%$ CI $0.45 \%$ to $0.71 \%$ ) reduced risk of mortality compared with their male counterparts. Higher income was associated with increased survival. There was a $30 \%$ (HR $0.70 ; 95 \%$ CI $0.50 \%$ to $0.99 \%$ ) reduction in risk of mortality for participants in the high quintile compared with lowest quintile of SEIFA. In model 2 (adjusted for sociodemographic and behavioural factors), smoking and
PAL were significantly associated with mortality, in addition to sex, income and SEIFA. There was an increased risk of mortality for ex-smokers (HR 1.34; 95\% CI 1.07 to 1.68$)$ and current smokers $(2.31 ; 95 \%$ CI 1.70 to 3.16$)$ compared with non-smokers. Compared with participants who lived a sedentary life, those who did moderate exercise had a significantly lower risk of mortality (HR 0.50 ; $95 \%$ CI 0.38 to 0.66 ).

The extent of an association between income and mortality accounted for by behavioural and metabolic factors, chronic conditions and medication use is shown in online supplementary table 2. A higher proportion of an association between income and mortality was explained by behavioural factors in men than women. Among participants $\geq 65$ years of age and in the highest income categories (US\$60 001-US\$80000 and >US\$80 $000), 22.2 \%$ and $21.4 \%$ of the association was accounted for by behavioural factors, respectively.

After adjusting for sociodemographic, behavioural and metabolic risk factors (model 3), mortality was significantly associated with income, SEIFA, smoking status and PAL, BMI, per cent predicted $\mathrm{FEV}_{1}$ and $\mathrm{HbA1}$. Compared with normal weight participants, those who were overweight and obese had a $24 \%(0.76 ; 95 \%$ CI $0.60 \%$ to $0.97 \%)$ and 

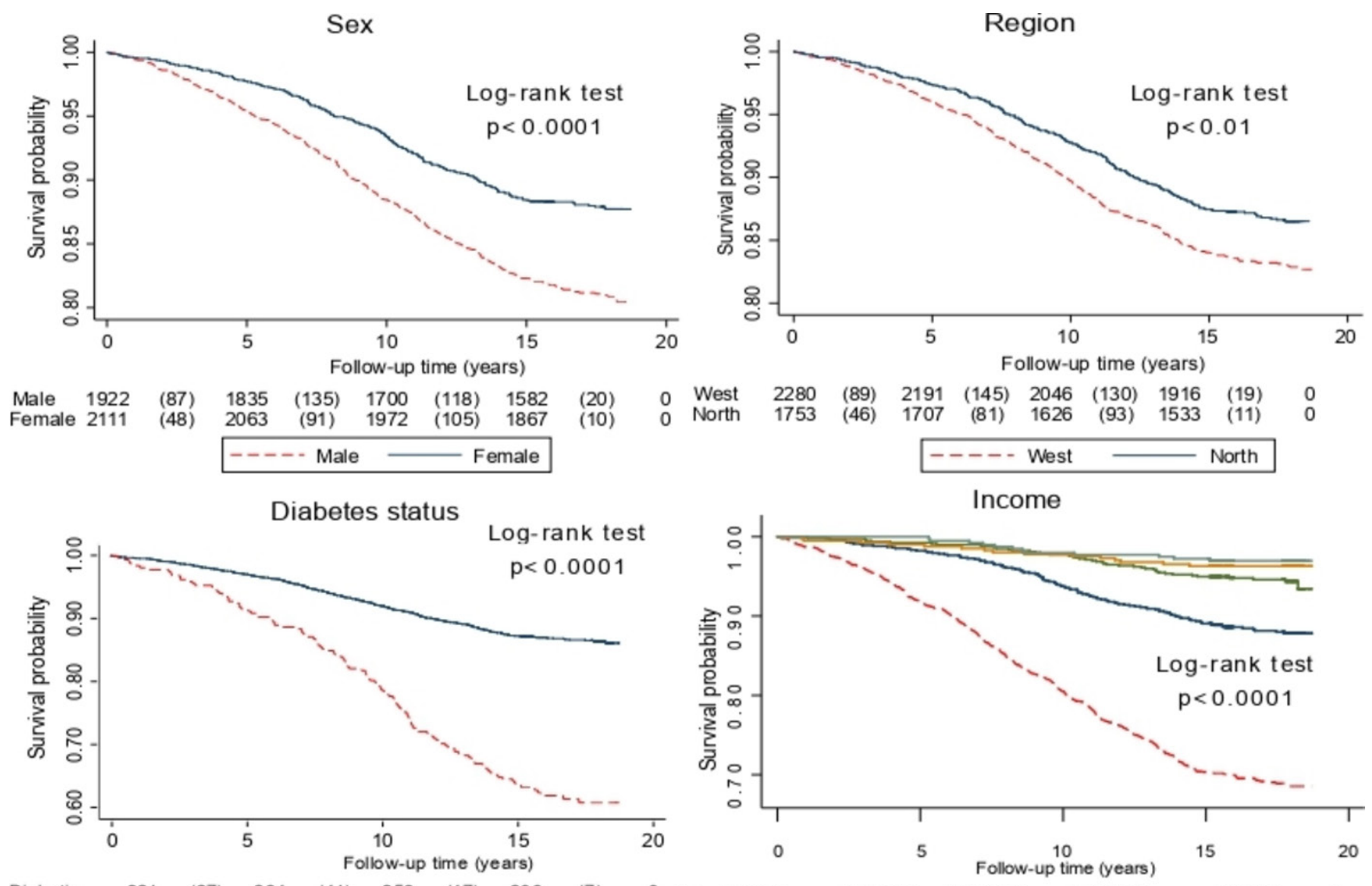

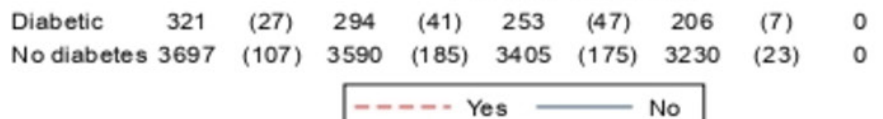

\begin{tabular}{|c|c|c|c|c|c|}
\hline Upto $\$ 20,000$ & $1183(95)$ & $1088(136)$ & $952(120)$ & $832(14)$ & 0 \\
\hline$\$ 20,001-\$ 40,000$ & $1024(18)$ & $1006(46)$ & 960 (48) & $912(9)$ & 0 \\
\hline$\$ 40,001-\$ 60,000$ & 796 (6) & $790(12)$ & $778 \quad(22)$ & 756 (4) & 0 \\
\hline$\$ 60,001-\$ 80,000$ & 406 & 402 (5) & $397 \quad(6)$ & $391(0)$ & 0 \\
\hline More than $\$ 80,000$ & 397 & $397 \quad(8)$ & $389 \quad(3)$ & 386 (1) & 0 \\
\hline
\end{tabular}

Figure 3 Kaplan-Meier survival estimate curve, life table and Log-rank $x^{2}$ test for sex, income, region of residence and diabetes status $(\mathrm{N}=4033 ; 614$ deaths).

an $11 \%$ (HR $0.89 ; 95 \%$ CI $0.61 \%$ to $1.31 \%$ ) reduction in risk of mortality, respectively. Whereas a $10 \%$ increase in lung function (per cent predicted $\mathrm{FEV}_{1}$ ) was associated with a $7 \%$ (HR $0.93 ; 95 \%$ CI $0.89 \%$ to $0.98 \%)$ reduced mortality risk, a unit increase in HbAlc increased the risk by $18 \%$ (HR $1.18 ; 95 \%$ CI $1.05 \%$ to $1.32 \%$ ) (table 2 ).

In model 4 (additionally adjusted for disease condition, medication and health service utilisation), reduced risk of mortality was associated with being separated or divorced, residence in the highest SEIFA quintile, engaging in moderate exercise, being overweight (BMI: $25.0-29.90 \mathrm{~kg} / \mathrm{m}^{2}$ ) and per $10 \%$ increase in per cent predicted $\mathrm{FEV}_{1}$. There was a $100 \%(\mathrm{HR} 2.00 ; 95 \% \mathrm{CI}$ $1.45 \%$ to $2.76 \%$ ) increase in risk of mortality of current smokers compared with non-smokers. The predictive performance (Somers' D index) of all models was more than $72 \%$ with a maximum of $75.1 \%$ for the final model (table 2). We did not find clustering of mortality by postal code (data not shown).
Sex-specific models are given in online supplementary tables 3 and 4. Separated/divorced men, but not women, had a significantly lower risk of all-cause mortality (HR 0.57 ; $95 \%$ CI 0.34 to 0.94 ) compared with those who were married or partnered (model 4). Whereas being an ex-smoker significantly increased the risk of mortality by $71 \%$ (HR $1.71 ; 95 \%$ CI $1.15 \%$ to $2.54 \%$ ) compared with non-smokers in women, no association was found in men (HR 1.05; 95\% CI 0.78 to 1.42). However, being a current smoker, compared with non-smoker, increased the risk of mortality in both sexes. The risk for current smokers increased by $138 \%$ (HR 2.38; $95 \%$ CI $1.41 \%$ to $4.00 \%$ ) in women and $85 \%$ (HR $1.85 ; 95 \%$ CI $1.21 \%$ to $2.83 \%$ ) in men. Moderate exercise level was found to be a protective factor against all mortality in both sexes. Compared with female participants who had a normal weight, women who were overweight had significantly lower risk of mortality (HR $0.63 ; 95 \%$ CI 0.42 to 0.96 ). There was no significant association between BMI and all-cause mortality in men (HR $0.84 ; 95 \%$ CI 0.58 to 1.22 ). 
Table 2 Associations (HRs and 95\% Cl) between participants' characteristics and mortality ( $n=3214 ; 432$ deaths)

\begin{tabular}{|c|c|c|c|c|c|}
\hline & & Model 1 & Model 2 & Model 3 & Model 4 \\
\hline Variable & Category & HR $(95 \% \mathrm{Cl})$ & HR $(95 \% \mathrm{Cl})$ & HR $(95 \% \mathrm{Cl})$ & HR $(95 \% \mathrm{Cl})$ \\
\hline Region & Western region & 1.00 & 1.00 & 1.00 & 1.00 \\
\hline Age & & 1.05 (0.98 to 1.12$)$ & 1.05 (0.98 to 1.12$)$ & 1.02 (0.96 to 1.09$)$ & 1.02 (0.95 to 1.09$)$ \\
\hline Age $x$ age & & 1.00 (1.00 to 1.00$)$ & 1.00 (1.00 to 1.00$)$ & $1.00^{*}(1.00$ to 1.00$)$ & $1.00^{*}(1.00$ to 1.00$)$ \\
\hline Sex & Wemen & $0.57^{\star \star}(0.45$ to 0.71$)$ & $0.57^{\star \star}(0.44$ to 0.74$)$ & $0.59^{\star \star}(0.45$ to 0.77$)$ & $0.58^{\star \star}(0.44$ to 0.76$)$ \\
\hline \multirow[t]{3}{*}{ Country of birth } & Australia & 1.00 & 1.00 & 1.00 & 1.00 \\
\hline & UK or Ireland & 1.23 (0.97 to 1.57$)$ & 1.21 (0.95 to 1.53$)$ & 1.20 (0.94 to 1.52$)$ & 1.24 (0.97 to 1.58$)$ \\
\hline & $\begin{array}{l}\text { Europe, the USSR } \\
\text { and the Baltic } \\
\text { states }\end{array}$ & 0.95 (0.71 to 1.28$)$ & 0.92 (0.68 to 1.23$)$ & 0.98 (0.73 to 1.32$)$ & 0.98 (0.72 to 1.33$)$ \\
\hline \multirow{3}{*}{ Education status } & $\begin{array}{l}\text { Trade/ } \\
\text { apprenticeship }\end{array}$ & $1.08(0.83$ to 1.40$)$ & 1.14 (0.88 to 1.48$)$ & 1.07 (0.83 to 1.40$)$ & 1.09 (0.84 to 1.42$)$ \\
\hline & Certificate/diploma & 1.12 (0.87 to 1.43$)$ & 1.24 (0.96 to 1.60$)$ & 1.24 (0.96 to 1.60$)$ & 1.22 (0.94 to 1.58$)$ \\
\hline & $\begin{array}{l}\text { Bachelor degree or } \\
\text { higher }\end{array}$ & 1.04 (0.65 to 1.67$)$ & 1.16 (0.72 to 1.86$)$ & 1.14 (0.71 to 1.82$)$ & 1.16 (0.72 to 1.86$)$ \\
\hline \multirow[t]{3}{*}{ Marital status } & $\begin{array}{l}\text { Married/living with } \\
\text { partner }\end{array}$ & 1.00 & 1.00 & 1.00 & 1.00 \\
\hline & Separated/divorced & 0.81 (0.57 to 1.14$)$ & 0.71 (0.50 to 1.00$)$ & 0.71 (0.50 to 1.01$)$ & $0.69^{*}(0.48$ to 0.98$)$ \\
\hline & Widowed & $0.96(0.74$ to 1.24$)$ & 0.90 (0.69 to 1.16$)$ & $0.91(0.70$ to 1.17$)$ & 0.89 (0.69 to 1.16$)$ \\
\hline \multirow{2}{*}{ Income per year } & $\begin{array}{l}\text { US\$60 001- } \\
\text { US\$80000 }\end{array}$ & 0.57 (0.32 to 1.02$)$ & 0.64 (0.36 to 1.13$)$ & 0.70 (0.39 to 1.25$)$ & 0.71 (0.40 to 1.28$)$ \\
\hline & $\begin{array}{l}\text { More than } \\
\text { US } \$ 80000\end{array}$ & $0.37^{\star \star}(0.18$ to 0.75$)$ & $0.42^{\star}(0.21$ to 0.86$)$ & $0.47^{\star}(0.23$ to 0.96$)$ & $0.49^{\star}(0.24$ to 1.00$)$ \\
\hline \multirow[t]{5}{*}{ SEIFA } & Lowest quintile & 1.00 & 1.00 & 1.00 & 1.00 \\
\hline & Low quintile & 1.11 (0.84 to 1.46$)$ & $1.10(0.84$ to 1.45$)$ & 1.09 (0.83 to 1.44$)$ & 1.09 (0.82 to 1.43$)$ \\
\hline & Middle quintile & $1.00(0.79$ to 1.27$)$ & 1.07 (0.84 to 1.37$)$ & $1.06(0.83$ to 1.35$)$ & 1.04 (0.82 to 1.33$)$ \\
\hline & High quintile & $0.70^{*}(0.50$ to 0.99$)$ & $0.70^{\star}(0.49$ to 0.98$)$ & $0.67^{\star}(0.47$ to 0.95$)$ & $0.65^{\star}(0.46$ to 0.93$)$ \\
\hline & Highest quintile & $0.97(0.59$ to 1.61$)$ & 1.07 (0.64 to 1.78$)$ & $1.04(0.62$ to 1.74$)$ & 1.08 (0.64 to 1.82$)$ \\
\hline \multirow[t]{3}{*}{ Alcohol risk } & $\begin{array}{l}\text { Non-drinkers (no } \\
\text { risk) }\end{array}$ & & 1.00 & 1.00 & 1.00 \\
\hline & Low risk & & 1.05 (0.82 to 1.35$)$ & $1.10(0.86$ to 1.40$)$ & 1.14 (0.89 to 1.47$)$ \\
\hline & $\begin{array}{l}\text { Intermediate to very } \\
\text { high risk }\end{array}$ & & $1.12(0.70$ to 1.77$)$ & $1.17(0.74$ to 1.86$)$ & 1.17 (0.73 to 1.86$)$ \\
\hline \multirow[t]{3}{*}{ Smoking status } & Non-smoker & & 1.00 & 1.00 & 1.00 \\
\hline & Ex-smoker & & $1.34^{*}(1.07$ to 1.68$)$ & $1.27^{*}(1.01$ to 1.60$)$ & 1.22 (0.97 to 1.54$)$ \\
\hline & Current smoker & & $2.31^{\star \star}(1.70$ to 3.16$)$ & $2.09^{\star \star}(1.52$ to 2.87$)$ & $2.00^{\star *}(1.45$ to 2.76$)$ \\
\hline
\end{tabular}


Table 2 Continued

\begin{tabular}{|c|c|c|c|c|c|}
\hline & & Model 1 & Model 2 & Model 3 & Model 4 \\
\hline Variable & Category & HR $(95 \% \mathrm{Cl})$ & HR $(95 \% \mathrm{Cl})$ & HR $(95 \%$ Cl) & HR $(95 \% \mathrm{Cl})$ \\
\hline \multirow[t]{4}{*}{ PAL } & Sedentary & & 1.00 & 1.00 & 1.00 \\
\hline & Low exercise level & & 0.82 (0.65 to 1.04$)$ & 0.87 (0.69 to 1.10$)$ & 0.89 (0.70 to 1.13$)$ \\
\hline & $\begin{array}{l}\text { Moderate exercise } \\
\text { level }\end{array}$ & & $0.50^{\star *}(0.38$ to 0.66$)$ & $0.55^{\star \star}(0.42$ to 0.72$)$ & $0.55^{\star \star}(0.42$ to 0.72$)$ \\
\hline & High exercise level & & 0.89 (0.61 to 1.31$)$ & 0.97 (0.66 to 1.42$)$ & 0.97 (0.66 to 1.43$)$ \\
\hline \multirow[t]{3}{*}{ BMI category } & $\begin{array}{l}\text { Normal }(18.50- \\
\left.24.99 \mathrm{~kg} / \mathrm{m}^{2}\right)\end{array}$ & & & 1.00 & 1.00 \\
\hline & $\begin{array}{l}\text { Overweight (25.00- } \\
\left.29.99 \mathrm{~kg} / \mathrm{m}^{2}\right)\end{array}$ & & & $0.76^{\star}(0.60$ to 0.97$)$ & $0.74^{*}$ (0.58 to 0.94$)$ \\
\hline & $\begin{array}{l}\text { Obese }(\geq 30.00 \mathrm{~kg} / \\
\left.\mathrm{m}^{2}\right)\end{array}$ & & & 0.94 (0.72 to 1.23$)$ & 0.89 (0.68 to 1.17$)$ \\
\hline $\begin{array}{l}\text { Systolic blood } \\
\text { pressure per } 10 \mathrm{~mm}\end{array}$ & & & & 1.04 (0.98 to 1.09$)$ & 1.04 (0.98 to 1.09$)$ \\
\hline
\end{tabular}

Hg increase

\begin{tabular}{|c|c|c|c|c|c|}
\hline $\begin{array}{l}\text { FEV (\%) per 10\% } \\
\text { increase }\end{array}$ & & & & $0.93^{\star *}(0.89$ to 0.98$)$ & $0.92^{\star *}(0.87$ to 0.97$)$ \\
\hline $\mathrm{HbA1c}$ & & & & $1.18^{\star \star}(1.05$ to 1.32$)$ & 1.08 (0.94 to 1.25$)$ \\
\hline Mental health & No & & & & 1.00 \\
\hline problem & Yes & & & & 0.91 (0.56 to 1.50$)$ \\
\hline Depression & No & & & & 1.00 \\
\hline & Yes & & & & 1.58 (0.87 to 2.87$)$ \\
\hline Diabetes & No & & & & 1.00 \\
\hline & Yes & & & & 1.37 (0.98 to 1.92$)$ \\
\hline CVD & No & & & & 1.00 \\
\hline & Yes & & & & 1.27 (0.99 to 1.62$)$ \\
\hline Hypertension & No & & & & 1.00 \\
\hline medication & Yes & & & & 1.24 (0.96 to 1.62$)$ \\
\hline Respiratory disease & No & & & & 1.00 \\
\hline & Yes & & & & 0.70 (0.43 to 1.13$)$ \\
\hline Cholesterol lowering & No & & & & 1.00 \\
\hline drug & Yes & & & & 0.76 (0.54 to 1.08$)$ \\
\hline $\begin{array}{l}\text { Health service } \\
\text { utilisation }\end{array}$ & & & & & 1.04 (0.97 to 1.10$)$ \\
\hline $\begin{array}{l}\text { Akaike information } \\
\text { criterion }\end{array}$ & & 6020.1 & 5976.9 & 5959.3 & 5956.3 \\
\hline $\begin{array}{l}\text { Bayesian information } \\
\text { criterion }\end{array}$ & & 6147.7 & 6147.0 & 6159.8 & 6205.4 \\
\hline Harrell's C index & & $86.3 \%$ & $87.0 \%$ & $87.4 \%$ & $87.6 \%$ \\
\hline Somers' D index & & $72.6 \%$ & $74.0 \%$ & $74.8 \%$ & $75.1 \%$ \\
\hline
\end{tabular}

Model 1 was adjusted for sociodemographic factors (region, age, sex, educational status, income, SEIFA and country of birth); model 2 was additionally adjusted for behavioural factors (smoking, physical activity and alcohol intake); model 3 was additionally adjusted formetabolic factors (BMI, systolic blood pressure, FEV and $\mathrm{HbA1c}$ ); model 4 was additionally adjusted for health status, medication use and health service utilisation (mental health status, depression, diabetes, cardiovascular disease, hypertension medication, respiratory medication, cholesterol lowering drug use and health service utilisation).

${ }^{*} \mathrm{P}<0.05,{ }^{* \star} \mathrm{P}<0.01$.

BMI, body mass index; CVD, cardiovascular disease; FEV , forced expiratory volume in $1 \mathrm{~s}$; HbA1c, glycosylated haemoglobin; PAL, physical activity level; SEIFA, Socioeconomic Indexes for Areas; USSR, Union of Soviet Socialist Republics. 
Age-stratified ( $<65$ and $\geq 65$ years of age) associations between covariates and all-cause mortality are shown in online supplementary tables 5 and 6 . Income, smoking and per cent predicted $\mathrm{FEV}_{1}$ were significant predictors of mortality among participants less than 65 years. Sex, SEIFA, smoking status, PAL, BMI and hypertension medications significantly predicted all-cause mortality in older age group (model 4$)$.

We found a significant interaction between diabetic status with region (HR 1.93; 95\% CI 1.15 to 3.22 ); $\mathrm{p}_{\text {interac- }}$ tion $=0.012$ ) and depression (HR 3.69; $95 \%$ CI 1.61 to 8.50 ; $\mathrm{p}=0.002$ ) in predicting all-cause mortality. Diabetes was more strongly associated with all-cause mortality in residents in the North than West. Similarly, diabetes was more strongly associated with all-cause mortality in depressed participants than in non-depressed (model 4).

All sensitivity analyses (using model 4) made little or no difference to estimated associations between predictors and all-cause mortality (data not shown). Correlation among covariates used in model 4 is shown in online Supplementary table 7 .

\section{DISCUSSION}

In this study, we comprehensively explored the role of sociodemographic and behavioural characteristics, metabolic and chronic conditions, medication and health service utilisation in predicting all-cause mortality in a community-dwelling population followed over nearly two decades. To our knowledge, this is the first study of its kind to investigate the long-term (18 years) mortality risk and its associated factors at a community level with a comprehensive assessment of participants' characteristics that included social, behavioural, metabolic and clinical data. We demonstrated that the most important predictors of all-cause mortality were sociodemographic and behavioural characteristics. In addition, predictors of mortality varied by sex and age brackets. We also found that the mortality risk of diabetic participants was modified by place of residence and depression. The study highlights the need to address social inequalities and strengthen behavioural interventions for different subgroups of population to prevent premature deaths.

\section{Sociodemographic predictors}

It is not surprising that the risk of all-cause mortality among women was lower than men in our study, especially in the older age group ( $\geq 65$ years). Despite this, women have higher rates of stress, anxiety, depression, non-fatal chronic conditions, and are more likely to encounter violence than men. ${ }^{23}$ In addition, there is a disparity in social equality between men and women, women in general experiencing less advantage. However, evidence shows that factors, including biological, behavioural, ${ }^{24}$ health awareness and risk perception, ${ }^{25}$ could explain these differences. Women are more likely to follow health recommendations and have a higher risk perception. ${ }^{26}$ For instance, in our study a higher proportion (50.8\%) of women never smoked compared with men (38.9\%). Conversely, $7.3 \%$ of men never used health services over the last 12 months before the baseline compared with $4.1 \%$ of women. In addition, men tend to be less adherent to medications. ${ }^{27}$ Although public health interventions may not address biological factors directly, such as testosterone, ${ }^{28}$ gender and other related factors could be focus areas for interventions to decrease the higher risk of mortality in men.

In our study, separated/divorced participants had a significantly lower risk of mortality than those who were married/partnered. Previous studies have consistently shown that married individuals (particularly men) had a lower risk of mortality and were more likely to report better health compared with unmarried counterparts. ${ }^{29}{ }^{30}$ This differences could be attributed to differences in quality of relationship, ${ }^{31}$ selection of participants, ${ }^{32}$ dynamicity of marital status, ${ }^{30} 33$ study design and model specification. One of the drawbacks in previous studies that investigated the association between marital status and mortality has been lack of comprehensive data that can be used to handle confounding and mediating effects of the aforementioned characteristics. ${ }^{31-34}$ In the current study, we were able to specify our model by incorporating comprehensive characteristics of participants, including metabolic, mental health and chronic conditions. In addition, stressful and unhelpful spousal behaviours could be another explanation for the difference ${ }^{32}$ on which we did not have data.

Subgroup analyses by age revealed similar association pattern between marital status and mortality in participants $<65$ and $\geq 65$ years of age, but without a statistical significance. The insignificant association could be due to inadequate sample size. The association between marital status and mortality remained significant in men but not in women. Studies have shown that the association between marital status and mortality was stronger in men than women but with beneficial effect of enduring marriage ${ }^{33} 34$ unlike the current study. Although inadequate sample size could be one of the explanations for our finding, other factors, such as a higher economic responsibility and associated stresses in married/partnered men than women, could explain the finding.

A higher annual household income was strongly associated with a lower risk of mortality, particularly in participants less than 65 years of age. There are continuing challenges of health policies as a result of socioeconomic inequalities, especially income differences. The impact of income inequality on morbidity and mortality exists in high-income countries. ${ }^{4}$ There is an association of socioeconomic inequalities with behavioural and other determinant factors of health in the Western countries. ${ }^{21}$ In our study, the extent of an association between income and mortality that was explained by other factors varied by population subgroups. In addition, our model that included only sociodemographic characteristics explained $71.5 \%$ of mortality. This implies that most of the differences in mortality risk are explained by social 
inequalities. Hence, addressing these social inequalities could reduce significant portion of premature deaths. Much evidence has accumulated to support social interventions as key to improving health outcomes. Despite that the healthcare delivery model has little changed over the past decade. As evident by our findings, tailored approaches are key in addressing health consequences of social inequality and it is time to move from observation to intervention.

\section{Behavioural predictors}

A higher risk of mortality was seen in current smokers and former women smokers. In addition, the association between smoking status and mortality was stronger in women than men. On the other hand, our study showed that the proportion of smokers was higher in men than in women. This suggests that even though women have less risk-taking behaviour ${ }^{35}$ and better risk perception ${ }^{25}$ than men, mortality risk associated with unhealthy behaviours is higher among women. Corroborated with the current study, evidence shows that women have a higher risk of morbidity and mortality associated with smoking. ${ }^{36} \mathrm{~A}$ study in Australia, however, reported a similar strength of association between current smokers and mortality for men and women. ${ }^{37}$ However, the study did not fully adjust for potential confounders, including physical activity and chronic conditions. We also found a stronger association between being current smoker and all-cause mortality in the younger age group ( $<65$ years) compared with the older age ( $\geq 65$ years). This may be explained by survival bias. In addition, in 2017/2018, the Australian Health Survey indicated that the prevalence of smoking gradually increased with a peak at the age of 45-54 years in both sexes, and then steadily declined onwards. ${ }^{38}$ In our analysis, we adjusted for lung function, which could account for the association between smoking and all-cause mortality or vice versa.

Moderate, but not vigorous, physical activity was associated with reduced risk of mortality. In line with our finding, a meta-analysis indicated that, compared with living a sedentary life, a moderate physical activity had a strong association with low risk of all-cause mortality. However, there was a minor additional risk reduction with further increase of activity level. ${ }^{39}$ This indicates that vigorous exercise could improve physical fitness but the benefit in terms of reducing all-cause mortality is minimal. On the other hand, reverse causality could explain our finding. Individuals who had known they had a higher risk of, or already had, chronic disease are more likely to do vigorous exercise than those who did not. In the subgroup analysis, the association between moderate exercise and reduced risk of mortality remained significant among participants older than 65 years but not in the younger age bracket.

In general, from the current study, it is evident that socioeconomic factors were more important than other factors in predicting mortality at all age and particularly among younger participants. In participants less than 65 years of age, sociodemographic factors explained $52.6 \%$ of our model compared with $39.4 \%$ in those greater than or equal to 65 years. However, behavioural factors could be more important than socioeconomic factors in older people unlike younger age. For instance, evidence has shown that older people gain more benefit from physical activity than younger individuals. ${ }^{39}$ It has been reported that physical activity in aged people improves efficacy (defined as the energy output/energy input or watts/oxygen consumption $\left(\mathrm{Vo}^{2}\right)$ compared with young subjects, although older individuals have lower exercise efficiency and capacity (measured by $\mathrm{Vo}_{2}$ ) ${ }^{40} \mathrm{~A}$ previous study demonstrated that even low PAL, compared with sedentary level, was associated with $22 \%$ reduction of all-cause mortality among people older than 64 years of age. ${ }^{41}$ Our study along with other previous studies suggests that interventions to increase physical activity to moderate level among the elderly is an effective strategy to reduce mortality.

\section{Metabolic predictors}

Compared with participants with normal BMI, those who were overweight had statistically significant reduction of all-cause mortality risk although a recent study in the UK has reported that normal BMI is associated with reduced risk of mortality. ${ }^{13}$ However, other studies consistently showed that overweight individuals had a better survival advantage compared with those of normal weight. ${ }^{42}{ }^{43}$ Reverse causation and confounding bias (particularly smoking) could explain the differences in findings. However, the sensitivity analysis that excluded smokers and those with short follow-up demonstrated that the association remained similar to the main analysis.

We observed heterogeneity in the association between BMI and all-cause mortality in different population subgroups. The association was not statistically significant in men and participants younger than 65 years of age. This could be due to small sample sizes in the subgroup analysis. Another explanation could be due to the fact that age and sex could modify the association between BMI and all-cause mortality risk..$^{13}$ On the other hand, this could indicate that the importance of nutritional reserves in older age. Further, improved treatments for diseases, particularly for CVD, may have greater effect at higher BMI. ${ }^{44}$ However, the likelihood of reverse causation is higher in older age groups. Due to increased prevalence of chronic diseases in older age and associated muscle mass loss, the use of BMI as a measure of adiposity may not be appropriate. ${ }^{12}$

This study is not without limitations. First, we were not able to include dietary information in our model because we did not have data at baseline. Second, data on mental health, depression and CVD were self-reports of a doctor diagnosis. The participants could have concealed conditions that were not diagnosed by doctor, although these conditions have apparent symptoms unlike other conditions, such as diabetes. Third, there could be changes in participants' characteristics after the baseline data 
collection. We were not able to take an account of these changes. Fourth, our analysis by region of residency (North and West) was not based on accurate geographical information. Lastly, unmeasured and residual confounding bias cannot be excluded.

In summary, this study, unlike most of the previous studies, included a comprehensive set of mortality risk factors, including metabolic, clinical and mental health predictors. It demonstrates that socioeconomic factors are the most important predictors of all-cause mortality in a community-dwelling population (particularly in young age bracket) followed for a long period of time. In addition, we found that the predictors of all-cause mortality could vary by subgroup population. This implies the need to address social inequalities to address premature deaths in communities. Addressing avoidable mortality in communities will require innovative strategies to deal with the challenging and significant problem of social inequality.

\section{Author affiliations}

${ }^{1}$ Adelaide Institute for Sleep Health, College of Medicine and Public Health, Flinders University, Adelaide, South Australia, Australia

${ }^{2}$ Adelaide Medical School, The University of Adelaide, Adelaide, South Australia, Australia

${ }^{3}$ The Health Observatory, Discipline of Medicine, The Queen Elizabeth Hospital Campus, University of Adelaide, Adelaide, South Australia, Australia

${ }^{4}$ Freemason's Centre for Men's Health, Discipline of Medicine, The University of Adelaide, Adelaide, South Australia, Australia

${ }^{5}$ Rheumatology Unit, The Queen Elizabeth and Royal Adelaide Hospitals, Adelaide, South Australia, Australia

${ }^{6}$ Faculty of Health and Medical Sciences, University of Adelaide, Adelaide, South Australia, Australia

${ }^{7}$ Lyell McEwin Hospital, Adelaide, South Australia, Australia

\section{Acknowledgements We gratefully acknowledge participants of this study.}

Contributors YAM, SLA, TG, CH, MAB and RJA contributed to study conception, design, methods and planning. YAM completed all statistical analyses, drafted the manuscript and managed revisions. All authors contributed in interpretation of the data and revisions and approved the final manuscript.

Funding The NWAHS was funded by the University of Adelaide, the South Australian Department of Health and The Queen Elizabeth Hospital for which the authors are grateful.

Disclaimer The funders had no role in analysing or reporting the data.

Map disclaimer The depiction of boundaries on the map(s) in this article do not imply the expression of any opinion whatsoever on the part of BMJ (or any member of its group) concerning the legal status of any country, territory, jurisdiction or area or of its authorities. The map(s) are provided without any warranty of any kind, either express or implied.

Competing interests None declared.

Patient consent for publication Not required.

Ethics approval Ethics approval was provided by Ethics of Human Research Committee of The Queen Elizabeth Hospital, Adelaide, South Australia.

Provenance and peer review Not commissioned; externally peer reviewed.

Data availability statement Data are available on request to RJA (robert.adams@ flinders.edu.au)

Open access This is an open access article distributed in accordance with the Creative Commons Attribution Non Commercial (CC BY-NC 4.0) license, which permits others to distribute, remix, adapt, build upon this work non-commercially, and license their derivative works on different terms, provided the original work is properly cited, appropriate credit is given, any changes made indicated, and the use is non-commercial. See: http://creativecommons.org/licenses/by-nc/4.0/.

\section{REFERENCES}

1. Institute for Health Metrics and Evaluation (IHME). GBD compare data visualization. Seattle, WA: IHME University of Washington, 2017. Available: http://vizhub.healthdata.org/gbd-compare [Accessed 8 January 2019].

2. Australian Institute of Health and Welfare. Deaths in Australia, 2016. AlHW, Canmberra. Available: https://www.aihw.gov.au/reports/lifeexpectancy-death/deaths-in-australia/contents/leading-causes-ofdeath [Accessed 9 January 2018].

3. GBD 2017 Risk Factor Collaborators. Global, regional, and national comparative risk assessment of 84 behavioural, environmental and occupational, and metabolic risks or clusters of risks for 195 countries and territories, 1990-2017: a systematic analysis for the Global Burden of Disease Study 2017. Lancet 2018;392:1923-94.

4. Mackenbach JP, Bopp M, Deboosere P, et al. Determinants of the magnitude of socioeconomic inequalities in mortality: a study of 17 European countries. Health Place 2017:47:44-53.

5. Roskam A-JR, Kunst AE, Van Oyen H, et al. Comparative appraisal of educational inequalities in overweight and obesity among adults in 19 European countries. Int J Epidemiol 2010;39:392-404.

6. Eikemo TA, Hoffmann R, Kulik MC, et al. How can inequalities in mortality be reduced? A quantitative analysis of 6 risk factors in 21 European populations. PLoS One 2014;9:e110952.

7. Hoffmann R, Eikemo TA, Kulhánová I, et al. Obesity and the potential reduction of social inequalities in mortality: evidence from 21 European populations. Eur J Public Health 2015;25:849-56.

8. Lantz PM, Golberstein E, House JS, et al. Socioeconomic and behavioral risk factors for mortality in a national 19-year prospective study of U.S. adults. Soc Sci Med 2010;70:1558-66.

9. Elovainio M, Hakulinen C, Pulkki-Råback L, et al. Contribution of risk factors to excess mortality in isolated and Lonely individuals: an analysis of data from the UK Biobank cohort study. Lancet Public Health 2017:2:e260-6.

10. Ganna A, Ingelsson E. 5 year mortality predictors in 498103 UK Biobank participants: a prospective population-based study. The Lancet 2015;386:533-40.

11. Yen Y-F, Hu H-Y, Lin I-F, et al. Associations of metabolic syndrome and its components with mortality in the elderly: a cohort study of 73,547 Taiwanese adults. Medicine 2015;94:e956.

12. $\mathrm{Ng} \mathrm{TP}$, Jin A, Chow KY, et al. Age-Dependent relationships between body mass index and mortality: Singapore longitudinal ageing study. PLoS One 2017;12:e0180818.

13. Bhaskaran K, Dos-Santos-Silva I, Leon DA, et al. Association of BM with overall and cause-specific mortality: a population-based cohort study of 3.6 million adults in the UK. Lancet Diabetes Endocrinol 2018;6:944-53.

14. Grant JF, Taylor AW, Ruffin RE, et al. Cohort profile: the North West Adelaide health study (NWAHS). Int J Epidemiol 2009;38:1479-86.

15. National Heart Foundation, Australian Institute of Health and Welfare. Risk factor prevalence study: survey No. 3. Canberra: NHF, 1989.

16. D'Onise R, Shanahan EM, Gill T, et al. Does leisure time physical activity protect against shoulder pain at work? Occup Med 2010;60:383-8.

17. McLennan W. National health survey: users' guide 1995. Canberra, Australia: Australian Bureau of Statistics, 1996.

18. Grant JF, Chittleborough CR, Taylor AW, et al. The North West Adelaide Health Study: detailed methods and baseline segmentation of a cohort for selected chronic diseases. Epidemiol Perspect Innov 2006;3:4

19. Appleton SL, Adams RJ, Wilson DH, et al. Spirometric criteria for asthma: adding further evidence to the debate. $J$ Allergy Clin Immunol 2005;116:976-82.

20. d'Emden M. Glycated haemoglobin for the diagnosis of diabetes. Aust Prescr 2014;37:98-100.

21. Laaksonen M, Talala K, Martelin T, et al. Health behaviours as explanations for educational level differences in cardiovascular and all-cause mortality: a follow-up of 60000 men and women over 23 years. Eur J Public Health 2008;18:38-43.

22. Newson RB. Comparing the predictive powers of survival models using Harrell's C or Somers' D. Stata J 2010;10:339-58.

23. GBD 2017 Disease and Injury Incidence and Prevalence Collaborators. Global, regional, and national incidence, prevalence, and years lived with disability for 354 diseases and injuries for 195 countries and territories, 1990-2017: a systematic analysis for the global burden of disease study 2017. Lancet 2018;392:1789-858.

24. Verdonk P, Seesing H, de Rijk A. Doing masculinity, not doing health? A qualitative study among Dutch male employees about health beliefs and workplace physical activity. BMC Public Health 2010;10:712-12.

25. Amuta AO, Jacobs W, Barry AE, et al. Gender differences in type 2 diabetes risk perception, attitude, and protective health behaviors: a 
study of overweight and obese college students. Am J Health Educ 2016:47:315-23.

26. Flynn J, Slovic P, Mertz CK. Gender, race, and perception of environmental health risks. Risk Anal 1994:14:1101-8.

27. Boullé C, Kouanfack C, Laborde-Balen G, et al. Gender differences in adherence and response to antiretroviral treatment in the Stratall trial in rural district hospitals in Cameroon. J Acquir Immune Defic Syndr 2015;69:355-64.

28. Assari S, Caldwell CH, Zimmerman MA. Sex differences in the association between testosterone and violent behaviors. Trauma Mon 2014;19:e18040-e40.

29. Van Hedel K, Van Lenthe FJ, Avendano M, et al. Marital status, labour force activity and mortality: a study in the USA and six European countries. Scand J Public Health 2015;43:469-80.

30. Robards J, Evandrou M, Falkingham J, et al. Marital status, health and mortality. Maturitas 2012;73:295-9.

31. Bookwala J. The role of marital quality in physical health during the mature years. J Aging Health 2005;17:85-104.

32. Joung IM, van de Mheen HD, Stronks K, et al. A longitudinal study of health selection in marital transitions. Soc Sci Med 1998;46:425-35.

33. Blomgren J, Martikainen P, Grundy E, et al. Marital history 197191 and mortality 1991-2004 in England \& Wales and Finland. $J$ Epidemiol Community Health 2012;66:30-6.

34. Hewitt B, Turrell G, Giskes K. Marital loss, mental health and the role of perceived social support: findings from six waves of an Australian population based panel study. J Epidemiol Community Health 2012;66:308-14.

35. Byrnes JP, Miller DC, Schafer WD. Gender differences in risk taking: a meta-analysis. Psychol Bull 1999;125:367-83.
36. Mucha L, Stephenson J, Morandi N, et al. Meta-Analysis of disease risk associated with smoking, by gender and intensity of smoking. Gend Med 2006;3:279-91.

37. Banks E, Joshy G, Weber MF, et al. Tobacco smoking and allcause mortality in a large Australian cohort study: findings from a mature epidemic with current low smoking prevalence. BMC Med 2015;13:38

38. Australian Bureau of Statistics. National health survey, 2017-18. Canberra. Available: http://www.abs.gov.au/ausstats/abs@.nsf/ Lookup/by\%20Subject/4364.0.55.001 2017-18 Main\%20Features Smoking 85 [Accessed 09 January 2019].

39. Löllgen H, Böckenhoff A, Knapp G. Physical activity and allcause mortality: an updated meta-analysis with different intensity categories. Int J Sports Med 2009;30:213-24.

40. Woo JS, Derleth C, Stratton JR, et al. The influence of age, gender, and training on exercise efficiency. J Am Coll Cardiol 2006;47:1049-57.

41. Hupin D, Edouard P, Gremeaux V, et al. Physical activity to reduce mortality risk. Eur Heart J 2017;38:1534-7.

42. Flegal KM, Kit BK, Orpana $\mathrm{H}$, et al. Association of all-cause mortality with overweight and obesity using standard body mass index categories: a systematic review and meta-analysis. JAMA 2013:309:71-82.

43. Wang Z, Liu M, Pan T, et al. Lower mortality associated with overweight in the U.S. National health interview survey. Medicine 2016;95:e2424-e24.

44. Gregg EW, Cheng YJ, Cadwell BL, et al. Secular trends in cardiovascular disease risk factors according to body mass index in US adults. JAMA 2005;293:1868-74. 